\title{
The effect of delayed reinforcement on DRL performance
}

DONALD MELTZER AND JAMES A. BRAHLEK SOUTHERN ILLINOIS UNIVERSITY

Stable DRL performance of four rats was studied under conditions of delayed reinforcement. A DRL $20 \mathrm{sec}$ requirement remained in effect across all sessions while the delay of reinforcement following a correct response was varied from 8 $\mathrm{sec}$ to $28 \mathrm{sec}$ in different blocks of sessions. For delays shorter than the DRL $20 \mathrm{sec}$ requirement, it was found that response rate was not affected by delay of reinforcement, each $S$ responding optimally for the schedule. However, for reinforcement delays longer than the $D R L$ requirement, each $S$ 's response rate decreased. This resulted in performance that was less than optimal for the schedule.

It has often been pointed out that delayed reinforcement reduces free operant response rate (Skinner, 1938; Perin, 1943; Azzi et al, 1964). However, Meltzer, Merkler, \& Maxey (1965) showed that a temporal discrimination-DRL 20 sec-could be acquired by rats when reinforcement was delayed by $10 \mathrm{sec}$ and the correct response was followed by a conditioned reinforcer. Under these contingencies all Ss increased their initially low response rates until modal interresponse times (IRTs) were just above $20 \mathrm{sec}$. This acquisition process was different from the reduction of initially high response rates usually seen when Ss are placed on a DRL schedule without delayed reinforcement. The final performance was similar to that reported (e.g., Sidman, 1956) when rats perform on a DRL schedule without delayed reinforcement.

Thus, the effect of delayed reinforcement on the acquisition of DRL performance has been demonstrated. In this experiment we investigated the relationship between duration of the delay interval and stable DRL performance. One variable which was of considerable interest was the posstbility of separating changes in reinforcement frequency (e.g., number of reinforcements per minute) from duration of delay interval. Merhod

The Ss were four 90 day old male albino rats bred in our laboratory. Each $\mathrm{S}$ was allowed $1 \mathrm{~h}$ of access to food immediately after an experimental session and was food deprived the rest of the time. Water was always available during feeding and in the home cage. Sessions were scheduled daily and lasted until $S$ had recelved 100 reinforcements, each consisting of a $45 \mathrm{mg}$ food pellet.

A commercially produced Skinner box (Lehigh Valley Model $1417 \mathrm{C}$ ) with interior dimensions of 7-3/8 $\times 12 \times$ 8 in. was used. The lever was on the front wall 1-3/4 in. above the floor and $1-3 / 4 \mathrm{in}$. from the left side of the chamber. The food hopper was also on the front wall, 2 in. from the right side and just above the floor.
A $7.5 \mathrm{~W}$ bulb above and to one side of the chamber was the only light source used.

The Ss were initially magazine trained and placed on a continuous reinforcement schedule. After three sessions all Ss were placed on a DRL 20 sec schedule of reinforcement. Each correct response was followed by $2 \mathrm{sec}$ light offset. Reinforcement was delivered $20 \mathrm{sec}$ after the response (1.e., $18 \mathrm{sec}$ after light was again turned on).

After 20 sessions the procedure was changed so that the light remained off for the entire 20 sec delay interval. Any response during the delay interval reset the DRL contingency but had no effect on the delivery of the scheduled reinforcement or the duration of the delay interval. Conditioning was continued until all four Ss showed stable response rates. Eleven sessions later the delay interval was changed and a series of different delay intervals was studied in successive blocks of sessions. Each $\mathrm{S}$ was run for 15 sessions at $16 \mathrm{sec}$ delay; 15 sessions at 12 sec delay; 15 additional sessions at 20 sec delay; 8 sessions at 28 sec delay; 12 sessions at 24 sec delay; and 15 sessions at $8 \mathrm{sec}$ delay, in that order. The DRL requirement was held at $20 \mathrm{sec}$ and the light remained off for the duration of the delay of reinforcement in every session.

IRTs were recorded on magnetic counters in $4 \mathrm{sec}$ bin widths during all sessions.

Results

Figure 1 shows the modes and interquartile ranges of each S's IRTs pooled over the last five sessions at a given delay interval. Responses made during the first $4 \mathrm{sec}$ were excluded from the calculations. There were many of these responses, but almost all of them represented bursts of responses which immediately followed a response terminating a long IRT. These burst responses were probably not under schedule control (cf., Sidman, 1956). Only the second block of $20 \mathrm{sec}$ delay sessions is shown in Fig. 1 since no differences in performance were evident when the two blocks of sessions at this delay value were compared.

The data showed that the modal IRT exceeded the duration of the delay interval at all delay values. For three of the four Ss, delays of 8,12 , or $16 \mathrm{sec}$ all resulted in a response distribution with a modal IRT in the 20-24 sec range. One S, R-1, had a modal IRT in the 24-28 sec range at 8 sec delay, but was in the 20-24 sec range at 12 and $16 \mathrm{sec}$ delays.

When the delay interval was $20 \mathrm{sec}$ or longer the modal IRT continued to exceed the delay. At the $20 \mathrm{sec}$ delay interval three of the four Ss had modal IRTs 


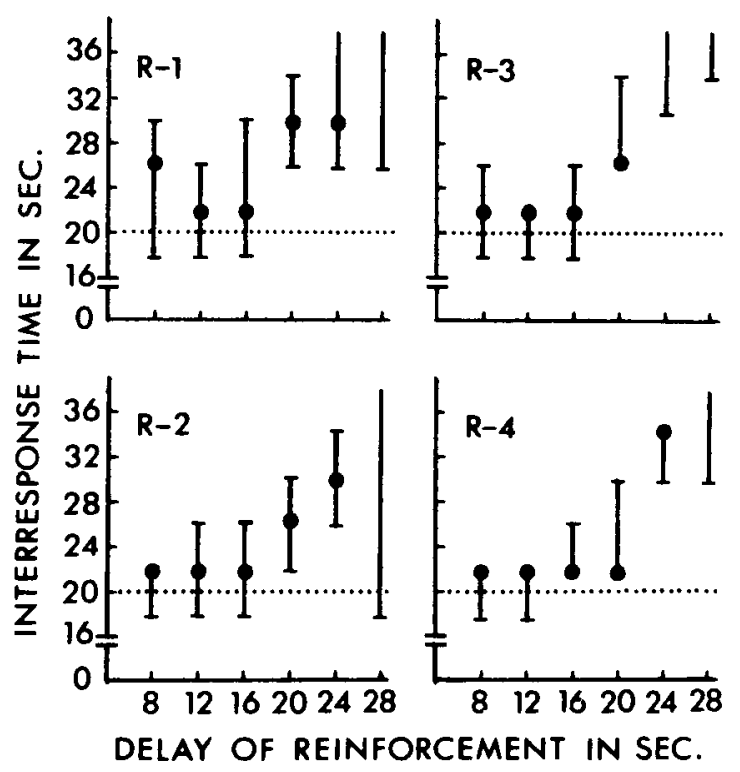

Fig. 1. Modes and interquartile ranges of interresponse times for the last five sessions at each delay.

longer than $24 \mathrm{sec}$; at a delay of $24 \mathrm{sec}$, all Ss had modal IRTs longer than $28 \mathrm{sec}$; and at a delay of $28 \mathrm{sec}$, all Ss made the majority of their responses after IRTs longer than $36 \mathrm{sec}$, and consequently it was impossible to determine the modal IRT. Although a higher proportion of responses was being reinforced at these longer delay intervals, the response rate was actually declining. Discussion

Several aspects of this performance conflict with data obtained from other studies of delayed reinforcement. The first, and most important difference, is the failure to find any change in response rate for delay intervals shorter than $20 \mathrm{sec}$. One factor which may account for this result is that a perfect temporal discrimination would still result in reinforcement every $20 \mathrm{sec}$. Most studies which have shown a decline in response rate when reinforcement was delayed (e.g., Skinner, 1938) have concurrently reduced reinforcement frequency. It is difficult to tell whether reduced frequency or delayed reinforcement actually caused the reduction in response rate. Our results suggest that the former conclusion may be correct.

Response rates in this experiment fell when the delay interval was longer than $20 \mathrm{sec}$. Although it would have been possible to obtain reinforcement every 20 sec under these conditions, $S$ would have had to emit a response during the delay interval. In fact, there were almost no responses by any $S$ during the delay interval, except for short bursts immediately following the onset of the conditioned reinforcer.

These results suggest that two discriminations controlled performance. One was a temporal discrimination based on the DRL schedule, and the other was a discrimination based on the complex of delay stimulus and reinforcement delivery. When the delay interval was shorter than the DRL requirement, responses in darkness-the conditioned reinforcer-were never reinforced. Responses in light were reinforced only when they met the DRL requirement, and consequently, the schedule controlled the behavior. However, when the delay equalled or exceeded the DRL requirement the suppression of responses in darkness meant, in effect, that almost every response in the light was reinforced. In that case light may have become a discriminative stimulus and bar pressing may have come under stimulus control rather than schedule control.

Another hypothesis may be viewed as either an alternative or complement to the possibility of stimulus control. This would be the assertion that a reduction in the programmed delay below $20 \mathrm{sec}$ did initially increase response rate. The rate increase in turn reduced reinforcement frequency and the reduced reinforcement frequency caused lower response rates. The Ss should thus have tended to reach a stable rate at which maximum reinforcement frequency was maintained. An increase in the programmed delay to more than $20 \mathrm{sec}$ produced a lower response rate. However, since almost all responses were already being reinforced, lower response rates simply reduced reinforcement frequency. Response rate would then have been expected to show a steady decline as both increased delay intervals and reduced reinforcement frequency took effect.

\section{References}

AZZI, R., FIX, DORA S. R., KELLER, F. A., \& ROCHA e SILVA, MARIA J. Exteroceptive control of response under delayed reinforcement. J. exp. Anal Behav., 1964, 7, 159-162.

GRICE, G. R. The relation of secondary reinforcement to delayed reward in visual discrimination learning. J. exp. Psychol, 1948, 38, 1-16.

MELTZER, D., MAXEY, G. C., \& MERKLER, N. L. The effect of delayed reinforcement on DRL conditioning. Psychon. Sci., 1965, 2, 331-332.

PERIN, C. T. The effect of delayed reinforcement upon the differentiation of bar responses in white rats. J. exp. Psychol, 1943, 32, 95-109.

PERKINS, C. C. Jr. The relation of secondary reward to gradients of reinforcement. J. exp. Psychol., 1947, 37, 377-392.

SIDMAN, M. Time discrimination and behavioral interaction in a free operant situation. J. comp. physiol. Psychol., 1956, 49, 469-473.

SKINNER, B. F. The behavior of organisms. New York: AppletonCentury, 1938 . 